Article

\title{
Patterned Well-Aligned ZnO Nanorods Assisted with Polystyrene Monolayer by Oxygen Plasma Treatment
}

\author{
Hyun Ji Choi ${ }^{1,2}$, Yong-Min Lee ${ }^{1}$, Jung-Hoon Yu ${ }^{1}$, Ki-Hwan Hwang ${ }^{1,2}$ and Jin-Hyo Boo ${ }^{1,2, *}$ \\ 1 Department of Chemistry, Sungkyunkwan University, Suwon 16419, Korea; \\ hyunjee3807@hanmail.net (H.J.C.); lymin87@naver.com (Y.-M.L.); thank42@hanmail.net (J.-H.Y.); \\ nercisus@naver.com (K.-H.H.) \\ 2 Institute of Basic Science, Sungkyunkwan University, Suwon 16419, Korea \\ * Correspondence: jhboo@skku.edu; Tel.: +82-031-290-5972
}

Academic Editor: Giorgio Biasiol

Received: 27 May 2016; Accepted: 2 August 2016; Published: 5 August 2016

\begin{abstract}
Zinc oxide is known as a promising material for sensing devices due to its piezoelectric properties. In particular, the alignment of $\mathrm{ZnO}$ nanostructures into ordered nanoarrays is expected to improve the device sensitivity due to the large surface area which can be utilized to capture significant quantities of gas particles. However, $\mathrm{ZnO}$ nanorods are difficult to grow on the quartz substrate with well-ordered shape. So, we investigated nanostructures by adjusting the interval distance of the arranged $\mathrm{ZnO}$ nanorods using polystyrene (PS) spheres of various sizes $(800 \mathrm{~nm}, 1300 \mathrm{~nm}$ and $1600 \mathrm{~nm}$ ). In addition, oxygen plasma treatment was used to specify the nucleation site of round, patterned $\mathrm{ZnO}$ nanorod growth. Therefore, $\mathrm{ZnO}$ nanorods were grown on a quartz substrate with a patterned polystyrene monolayer by the hydrothermal method after oxygen plasma treatment. The obtained $\mathrm{ZnO}$ nanostructures were characterized by X-ray diffraction (XRD) and field-emission scanning electron microscope (FE-SEM).
\end{abstract}

Keywords: $\mathrm{ZnO}$ nanorods; hydrothermal method; polystyrene monolayer; oxygen plasma treatment

\section{Introduction}

Zinc oxide is a semiconductor with a wide band gap of about $3.37 \mathrm{eV}$ (at $300 \mathrm{~K}$ ), a large free exciton-binding energy of $60 \mathrm{meV}$, high mechanical and thermal stabilities, and radiation hardness. To take advantage of these properties, nanostructures of $\mathrm{ZnO}$ have attracted both scientific and industrial interest owing to the possibility of being used in devices. Among the various nanostructures of $\mathrm{ZnO}$, one-dimensional (1D) structures, such as nanowires, nanorods, nanotubes and nanoflowers, have attracted extensive attention over the past few years, due to their unique semiconducting and piezoelectric properties [1,2]. In particular, the alignment of $\mathrm{ZnO}$ nanorods into ordered nanoarrays has been extensively studied for use in various nanotechnology applications such as surface acoustic wave devices [3], gas sensors [4], UV lasers [5] and dye-sensitized solar cells [6].

Various methods have been developed and introduced to synthesize $\mathrm{ZnO}$ nanorods, including chemical vapor deposition (CVD), metal organic chemical vapor deposition (MOCVD) [7], vapor-liquid-solid (VLS) growth [8], sputtering [9] and pulsed laser deposition [10]. However, these growth methods require relatively high synthesis temperatures $\left(>350{ }^{\circ} \mathrm{C}\right)$. In recent years, low-temperature approaches, such as the hydrothermal method, electro-deposition [11] and sol-gel processing [12], have become more important. Also, the hydrothermal method has the advantages of simple, large-scale product yield and sample uniformity at a relatively low temperature $\left(60-100{ }^{\circ} \mathrm{C}\right)$ compared to the previously mentioned methods $[13,14]$. Therefore, the use of hydrothermal synthesis has allowed researchers to simply obtain the $\mathrm{ZnO}$ nanorods. 
In order to apply $\mathrm{ZnO}$ nanorods to various sensing devices such as surface acoustic wave (SAW) sensors and quartz crystal microbalances $(\mathrm{QCM})$, the nanorods have to be grown on a quartz substrate with piezoelectric properties. One of the problems associated with $\mathrm{ZnO}$ nanorods is the difficulty to achieve a well-ordered growth on the quartz substrate [15]. In order to overcome this problem, one approach for preparing well-ordered nanostructures with promising cost-effectiveness and high throughput is the colloidal crystal template approach using self-assembled mono-disperse polystyrene (PS) spheres as a template [16,17]. Also, $\mathrm{ZnO}$ nanorods have been fabricated on c-oriented $\mathrm{ZnO}$ seed layers by hydrothermal growth, particularly exploring the effects of annealing or plasma pre-treating the seed layer $[18,19]$. Such pre-treatments influence the density, size and surface defects of particles within the nucleating seed layer, which impact the subsequent nanorod growth via sequential reactions with $\mathrm{OH}^{-}$and $\mathrm{Zn}^{2+}$ species. So, the oxygen plasma treatment prior to growing $\mathrm{ZnO}$ nanorods affects the nucleation. In this study, we investigate the patterned $\mathrm{ZnO}$ nanorods that were grown on a quartz substrate by partial oxygen plasma treatment using monolayers of PS spheres of various-diameters.

\section{Results and Discussion}

Figure $1 \mathrm{a}-\mathrm{c}$ shows the effect of the various reaction times on the polystyrene sphere size in the dispersion polymerization of styrene. Field-emission scanning electron microscopy (FE-SEM) images of synthesized PS spheres show that they have a highly uniform diameter. With increasing the reaction time, the size of the PS spheres increased proportionally $(800 \mathrm{~nm}, 1300 \mathrm{~nm}$ and $1600 \mathrm{~nm})$. Figure $1 \mathrm{~d}-\mathrm{f}$ shows the ordered PS sphere monolayer obtained through the conventional air-water interface-mediated method. Blowing air leads to the improvement of the crystal domain size by assisting recrystallization in the self-assembly process.

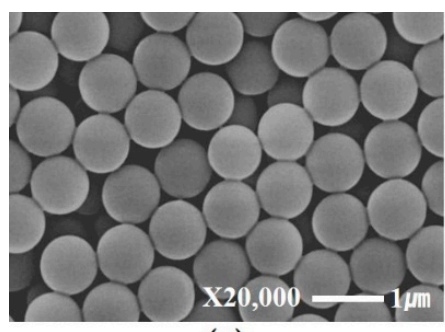

(a)

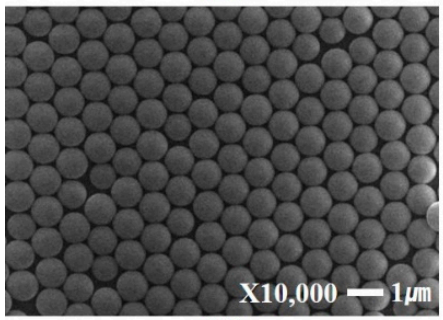

(d)

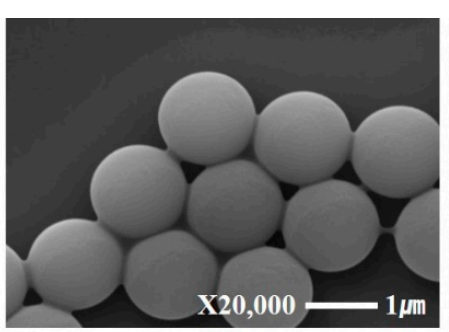

(b)

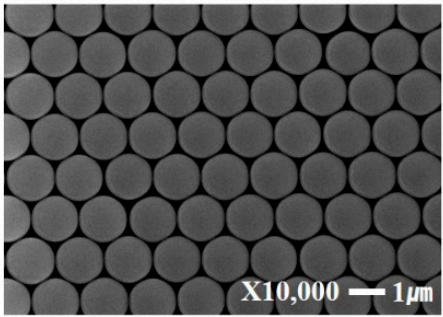

(e)

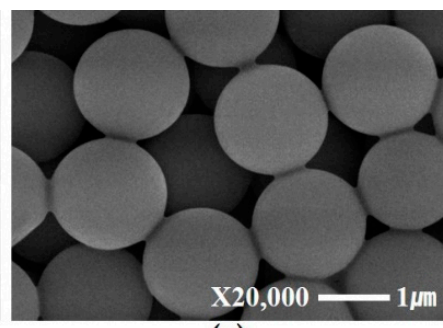

(c)

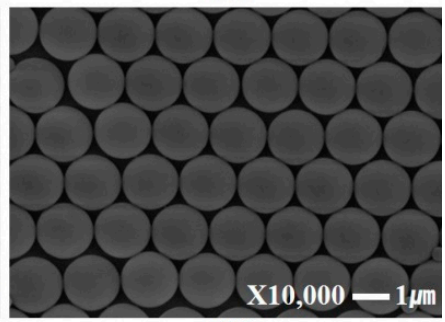

(f)

Figure 1. FE-SEM images of synthesized PS spheres with diameters of about (a) $800 \mathrm{~nm}$; (b) $1300 \mathrm{~nm}$; (c) $1600 \mathrm{~nm}$ and monolayers of (d) $800 \mathrm{~nm}$; (e) $1300 \mathrm{~nm}$ and (f) $1600 \mathrm{~nm}$.

The crystal structure and the orientation of the as-grown nanorods array were revealed by $X$-ray diffraction (XRD) investigation. Figure 2 shows a typical XRD pattern of the vertically aligned $\mathrm{ZnO}$ nanorod-assisted PS sphere monolayer on the quartz substrate (with and without oxygen plasma treatment). The XRD pattern shows the hexagonal (wurtzite) structure of the $\mathrm{ZnO}$ nanorods (JCPDS No. 87-0713) and the quartz substrate (JCPDS No. 46-1045). The as-grown ZnO nanorod arrays show good crystallinity with a significantly intensified reflection of (002) at a $2 \theta$ value of $34.48^{\circ}$, indicating a preferential orientation of the nanorods with the c-axis perpendicular to the quartz substrate. In the case of $\mathrm{ZnO}$ nanorods without the oxygen plasma treatment, the intensity of the (002) peaks was very weak. On the other hand, the (002) reflection peaks of the $\mathrm{ZnO}$ nanorods with 
oxygen plasma treatment were higher intensity than without oxygen plasma treatment. The higher intensity of the (002) reflection peaks showed that the $\mathrm{ZnO}$ nanorods with the oxygen plasma treatment were in more vertical alignment than those without the oxygen plasma treatment.

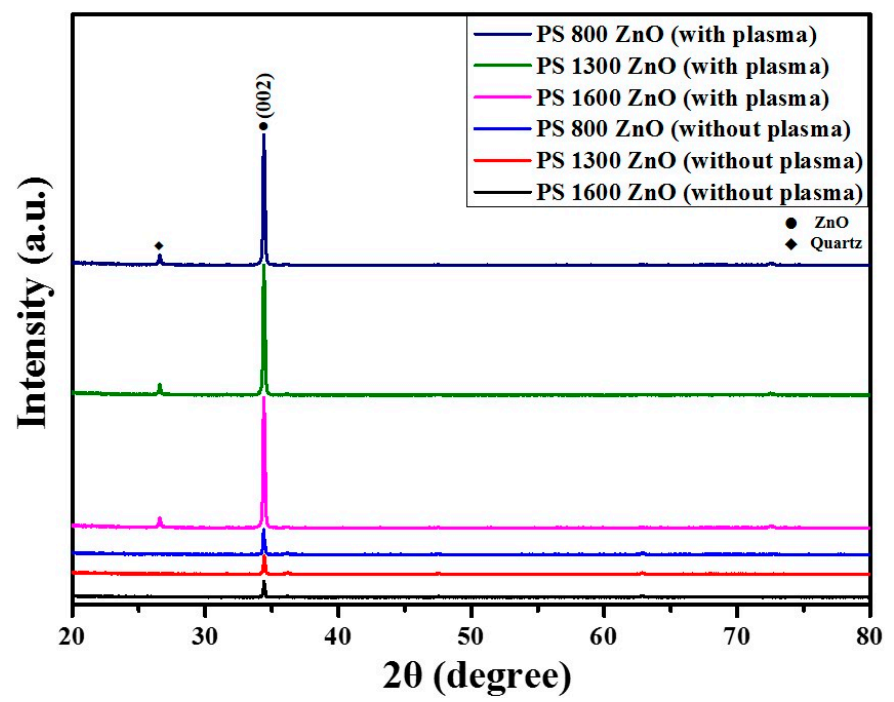

Figure 2. X-ray diffraction pattern of $\mathrm{ZnO}$ nanorod-assisted PS sphere monolayer arrays grown on a quartz substrate (with and without oxygen plasma treatment).

Figure 3 shows a set of FE-SEM images corresponding to an array of round, patterned $\mathrm{ZnO}$ nanorods prepared by a hydrothermal method on a quartz substrate modified with an assembly of a polystyrene monolayer template with spheres that are $800 \mathrm{~nm}, 1300 \mathrm{~nm}$ and $1600 \mathrm{~nm}$ in diameter. This pattern is due to the elimination of the PS spheres after $\mathrm{ZnO}$ nanorod growth. The resulting length of the $\mathrm{ZnO}$ nanorods grown for $6 \mathrm{~h}$ at $90^{\circ} \mathrm{C}$ in the same condition was approximately $2.6 \mu \mathrm{m}$. The oxygen plasma treatment is used to specify the nucleation site of the round, patterned $\mathrm{ZnO}$ nanorod growth.

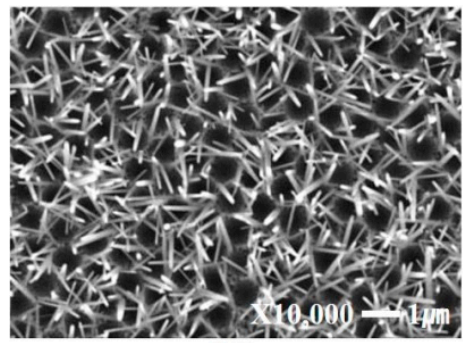

(a)

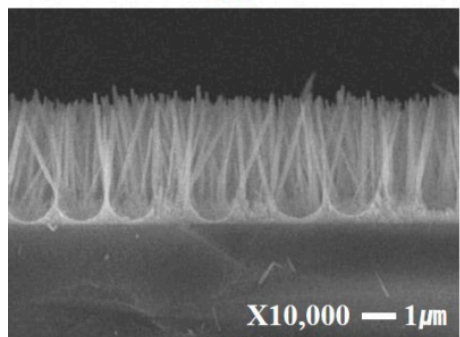

(d)

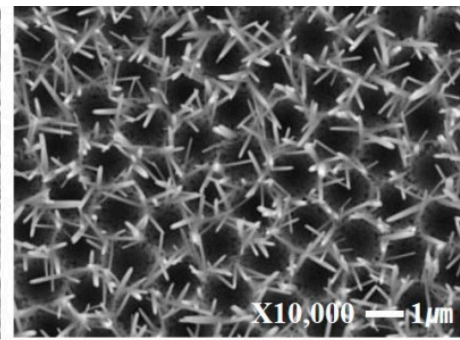

(b)

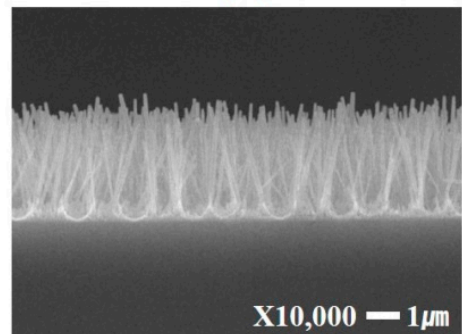

(e)

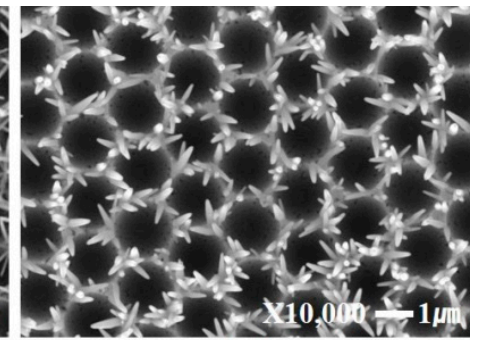

(c)

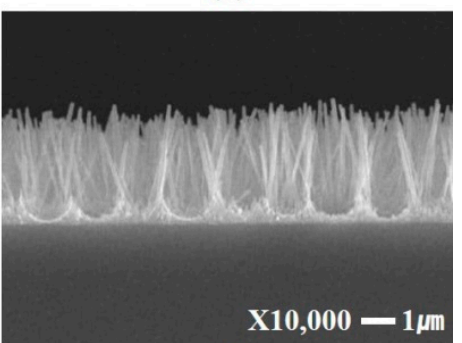

(f)

Figure 3. FE-SEM images of $\mathrm{ZnO}$ nanorod growth on quartz substrate using a PS monolayer template with oxygen plasma treatment. Diameters of polystyrene are (a) $800 \mathrm{~nm}$; (b) $1300 \mathrm{~nm}$; (c) $1600 \mathrm{~nm}$ and cross-section of (d) $800 \mathrm{~nm}$; (e) $1300 \mathrm{~nm}$ and (f) $1600 \mathrm{~nm}$, respectively. 
As shown in Figure 4, the resulting length of the $\mathrm{ZnO}$ nanorods was approximately $740 \mathrm{~nm}$. In normal cases (without oxygen plasma treatment), the seed layer/PS/solution interface has a higher surface energy than the unscreened surface (seed layer/solution interface). Therefore, there is greater possibility of forming the nucleation site at the seed layer/PS/solution interface than at the unscreened surface. Thus, $\mathrm{ZnO}$ nanorods did not completely accomplish a patterned structure. However, when the oxygen plasma treatment is used before growth, the unscreened areas are directly exposed to the plasma gas, causing an increase in the nucleation possibility and leading to preferential growth at the aperture site of the PS monolayer. In the (002) plane, the polar surface with -OH terminal groups contributes to vertically guiding these nanorods as a result of the strong bonding force, thus allowing a greater growth rate along this plane [20]. In other words, although the $\mathrm{ZnO}$ nanorods were grown for $6 \mathrm{~h}$, the nanorods grew at a faster rate, compared to the case of those without the oxygen plasma treatment. Also, by using the PS sphere monolayer, oxygen plasma treatment not only was selectively carried out but also controlled the regular intervals of $\mathrm{ZnO}$ nanorods. Therefore, $\mathrm{ZnO}$ nanorods could be grown with selective and rapid growth rates.

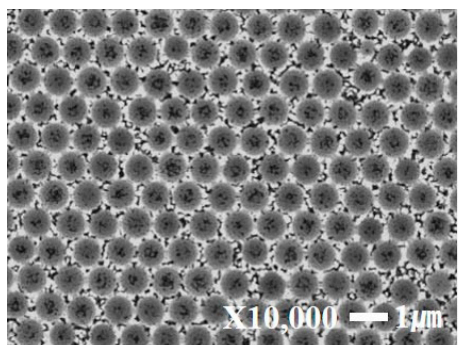

(a)

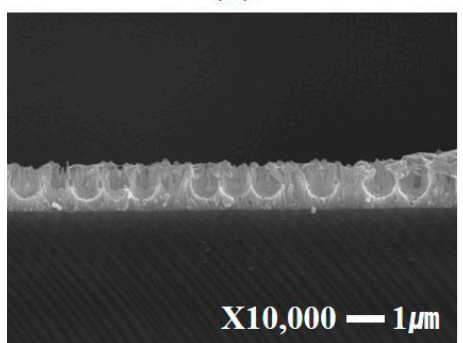

(d)

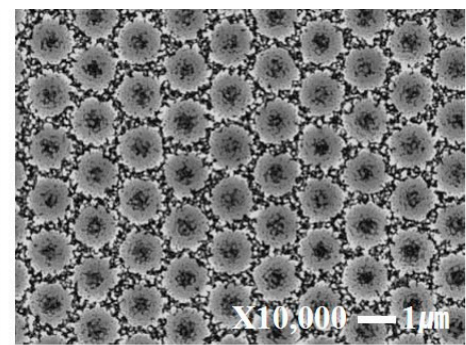

(b)

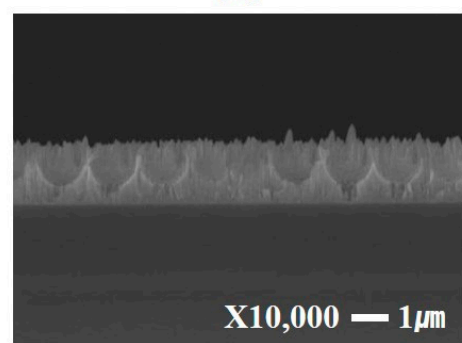

(e)

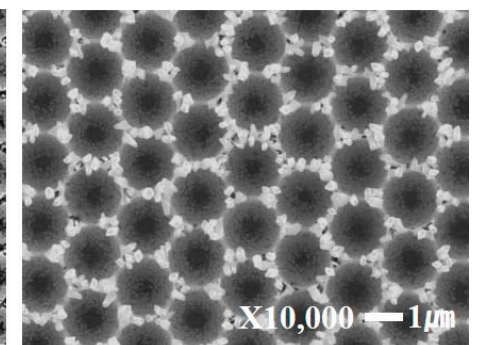

(c)

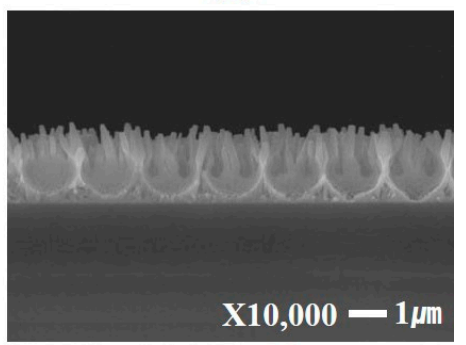

(f)

Figure 4. FE-SEM images of $\mathrm{ZnO}$ nanorod growth on quartz substrate by PS monolayer template without oxygen plasma treatment. Diameters of polystyrene are (a) $800 \mathrm{~nm}$; (b) $1300 \mathrm{~nm}$; (c) $1600 \mathrm{~nm}$ and cross-section of (d) $800 \mathrm{~nm}$; (e) $1300 \mathrm{~nm}$ and (f) $1600 \mathrm{~nm}$, resepectively.

\section{Materials and Methods}

\subsection{Synthesis of Polystyrene}

The polystyrene (PS) spheres with diameters of a few hundred nanometers were synthesized using dispersion polymerization. Briefly, the polymerization was carried out in an alcohol solvent system with 2,2-azobis(2-methylbutyronitrile) (AIBN, >98.0\%, Tokyo Chemical Industry Co., Ltd., Tokyo, Japan) as an initiator. The flask was filled with $100 \mathrm{~mL}$ of ethyl alcohol (EtOH, Daejung Chemical Co., Ltd., Siheung, Korea), $0.1 \mathrm{~g}$ AIBN, $10 \mathrm{~mL}$ styrene ( $\geqslant 99.0 \%$, Sigma-Aldrich, Munich, Germany) and polyvinyl pyrrolidone (PVP K-30, MW = 40,000 g/mol, Sigma-Aldrich) as stabilizer with magnetic stirring and nitrogen purging for $1 \mathrm{~h}$. Then, the mixed solution was heated at $60{ }^{\circ} \mathrm{C}$ and sufficiently bubbled with nitrogen gas to eliminate the dissolved oxygen, which act as inhibitor in polymerization step. When the temperature of the reaction mixture remains steady at about $60{ }^{\circ} \mathrm{C}$, the reaction proceeded. Detailed polymerization conditions are listed in Table 1. 
Table 1. Polymerization conditions for the obtention of PS spheres.

\begin{tabular}{ccccccc}
\hline $\begin{array}{c}\text { Size } \\
(\mathbf{n m})\end{array}$ & $\begin{array}{c}\text { Solvent } \\
\mathbf{( m L )}\end{array}$ & $\begin{array}{c}\text { Styrene } \\
\mathbf{( m L )}\end{array}$ & $\begin{array}{c}\text { Initiator } \\
\mathbf{( g )}\end{array}$ & $\begin{array}{c}\text { Stabilizer } \\
\mathbf{( g )}\end{array}$ & $\begin{array}{c}\text { Reaction } \\
\text { Time }(\mathbf{h})\end{array}$ & $\begin{array}{c}\text { Reaction } \\
\text { Temp. }\left({ }^{\circ} \mathbf{C}\right)\end{array}$ \\
\hline PS 1600 & EtOH 100 & 10 & 0.1 & 1.0 & 24 & 60 \\
PS 1300 & EtOH 100 & 10 & 0.1 & 1.0 & 16 & 60 \\
PS 800 & EtOH 100 & 10 & 0.1 & 1.0 & 8 & 60 \\
\hline
\end{tabular}

\subsection{Growth of Patterned $\mathrm{ZnO}$ Nanorods}

Prior to the growth of the $\mathrm{ZnO}$ nanorods, Zinc acetate dehydrate $\left(\mathrm{Zn}\left(\mathrm{CH}_{3} \mathrm{COO}\right)_{2} \cdot 2 \mathrm{H}_{2} \mathrm{O}\right.$, Extra pure, Duksan, Ansan, Korea) was dissolved into 2-methoxyethanol $\left(\mathrm{C}_{3} \mathrm{H}_{8} \mathrm{O}_{2},>99.0 \%\right.$, Tokyo Chemical Industry Co., Ltd.) containing ethanolamine $\left(\mathrm{C}_{2} \mathrm{H}_{7} \mathrm{NO}, \geqslant 99.0 \%\right.$, Sigma-Aldrich) and aged for two weeks with continuous stirring at room temperature. Before seed layer spin coating, the quartz substrate was cleaned with dilute hydrochloric acid, distilled water and ethanol for $10 \mathrm{~min}$ by sonication, respectively. After that, the quartz substrate was coated using the spin coating method (4000 rpm, $30 \mathrm{~s}$ ) and annealed in a furnace at $500{ }^{\circ} \mathrm{C}$ for $30 \mathrm{~min}$ to secure the proper crystallinity for the growth of the nanorods.

Then the PS solution was slowly dropped on a water surface using a petri-dish which was tilted with respect to the water surface using micro-pipette. Then, SDS (Sodium dodecyl sulfate, $\geqslant 99.0 \%$, Sigma-Aldrich) of surfactant was added on the water. On contact with the water, the PS spheres are spread and form a monolayer. Before being crystallized, air blowing was applied to the monolayer to induce the recrystallization of disordered PS spheres. Thus, the PS monolayer was transferred onto the seed coated substrate. PS layer coated substrate was dried under atmospheric condition. Then, the gap between $\mathrm{ZnO}$ nanorods was adjusted in three PS spheres sizes: $800 \mathrm{~nm}, 1300 \mathrm{~nm}$ and $1600 \mathrm{~nm}$. Before $\mathrm{ZnO}$ nanorod growth, the oxygen plasma treatment (Covance-MPR, Femto Science Inc., Yongin, Korea) condition was $100 \mathrm{sccm}, 100 \mathrm{~W}$ and $3 \mathrm{~min}$ for oxygen gas flow rate, plasma power, and time, respectively. For the growth of $\mathrm{ZnO}$ nanostructures on the patterned quartz substrate, zinc nitrate hexahydrate $\left(\mathrm{Zn}\left(\mathrm{NO}_{3}\right)_{2}, 10 \mathrm{mM},>98.0 \%\right.$, Sigma-Aldrich) and hexamethlyene tetramine (HMTA, $10 \mathrm{mM}, \geqslant 99.0 \%$, Sigma-Aldrich) were used as reacting agents in aqueous solution at room temperature for $2 \mathrm{~h}$. Then $\mathrm{ZnO}$ nanorods were grown on the as-prepared patterned seed layer with the layer floating face-down in a Teflon bath. The reactions were carried out in an autoclave reactor (AID TR24, Aid Engineering, Hwaseong, Korea) at $90{ }^{\circ} \mathrm{C}$ for $6 \mathrm{~h}$. After the reaction, the $\mathrm{ZnO}$ nanorod samples were calcined at $500{ }^{\circ} \mathrm{C}$ for $30 \mathrm{~min}$ to remove PS spheres. The crystal structure of the $\mathrm{ZnO}$ nanorods was characterized by X-ray diffraction (XRD, Bruker D8 Advance System, Dillerica, MA, USA) with filtered $\mathrm{Cu}(\mathrm{k} \alpha)$ radiation. The SEM images of the $\mathrm{ZnO}$ nanorods were measured by the field-emission scanning electron microscope (FE-SEM, JSM-7100F, JEOL, Tokyo, Japan).

\section{Conclusions}

In this work, the PS sphere monolayer-based patterning process was employed to control the shape, position, and orientation of the grown nanostructures through hydrothermal growth. Also, controlling the growth site structurally, the oxygen plasma treatment was confirmed to strongly affect the morphological structure of grown $\mathrm{ZnO}$ nanostructures. In addition, the comparative results of the $\mathrm{ZnO}$ nanorods with and without the oxygen plasma treatment were shown in this study; after the oxygen plasma treatment, the patterned $\mathrm{ZnO}$ nanorods became more highly ordered and grew more vertically.

Therefore, the alignment of $\mathrm{ZnO}$ nanostructures into ordered nanoarrays is expected to improve device sensitivity due to the increase in surface area to capture more gas particles. Moreover, this procedure could contribute to the development of optimized patterning of $\mathrm{ZnO}$ nanorod-based sensing devices, such as SAW sensors and QCM, and applied alignment of the sensitive structures can maximize the active areas of the sensors. 
Acknowledgments: This work was supported by the Agency for Defense Development through the Chemical and Biological Defense Research Center (CBD-12) and the National Research Foundation of Korea (NRF) with a grant funded by the Korean government (MSIP) (NRF-2010-0027963).

Author Contributions: Ki-Hwan Hwang and Jin-Hyo Boo conceived and designed the experiments; Hyun Ji Choi, Yong-Min Lee and Jung-Hoon Yu performed the experiments and analyzed the data; Ki-Hwan Hwang contributed reagents/materials/analysis tools; Hyun Ji Choi wrote the paper.

Conflicts of Interest: The authors declare no conflict of interest.

\section{Abbreviations}

The following abbreviations are used in this manuscript:

$\begin{array}{ll}\text { ZnO } & \text { Zinc oxide } \\ \text { PS } & \text { Polystyrene } \\ \text { FE-SEM } & \text { Field-emission scanning electron microscope } \\ \text { XRD } & \text { X-ray diffraction } \\ \text { rpm } & \text { Rounds per minute } \\ \text { sccm } & \text { Standard cubic centimeter per minute }\end{array}$

\section{References}

1. Qiu, J.; Li, X.; He, W.; Park, S.J.; Kim, H.K.; Hwang, Y.H.; Lee, J.H.; Kim, Y.D. The growth mechanism and optical properties of ultralong $\mathrm{ZnO}$ nanorod arrays with a high aspect ratio by a preheating hydrothermal method. Nanotechnology 2009, 20, 155603-155612. [PubMed]

2. Amin, G.; Asif, M.H.; Zainelabdin, A.; Zaman, S.; Nur, O.; Willander, M. Influence of pH, precursor concentration, growth time, and temperature on the morphology of $\mathrm{ZnO}$ nanostructures grown by the hydrothermal method. J. Nanomater. 2011, 2011, 1-9. [CrossRef]

3. Wang, Z.L.; Song, J. Piezoelectric nanogenerators based on zinc oxide nanowire arrays. Science 2006, 312, 242-246. [CrossRef] [PubMed]

4. Li, C.C.; Du, Z.F.; Li, L.M.; Yu, H.C.; Wan, Q.; Wang, T.H. Surface-depletion controlled gas sensing of ZnO nanorods grown at room temperature. Appl. Phys. Lett. 2007, 91, 032101-032103. [CrossRef]

5. Huang, M.H.; Mano, S.; Feick, H.; Yan, H.; Wu, Y.; Kind, H.; Weber, E.; Russo, R.; Yang, P. Room-temperature ultraviolet nanowire nanolasers. Science 2001, 292, 1897-1899. [CrossRef] [PubMed]

6. Son, D.Y.; Im, J.H.; Kim, H.S.; Park, N.G. 11\% efficient perovskite solar cell based on ZnO nanorods: An effective charge collection system. J. Phys. Chem. C 2014, 118, 16567-16573. [CrossRef]

7. Wu, J.J.; Liu, S.C. Low-temperature growth of well-aligned $\mathrm{ZnO}$ nanorods by chemical vapor deposition. Adv. Mater. 2002, 14, 215-218. [CrossRef]

8. Wang, X.; Summers, C.J.; Wang, Z.L. Large-scale hexagonal-patterned growth of aligned ZnO nanorods for nano-optoelectronics and nanosensor arrays. Nano Lett. 2004, 4, 423-426. [CrossRef] [PubMed]

9. Chen, M.T.; Ting, J.M. Sputter deposition of $\mathrm{ZnO}$ nanorods/thin-film structures on Si. Thin Solid Films 2006, 494, 250-254. [CrossRef]

10. Sun, Y.; Fuge, G.M.; Ashfold, M.N.R. Growth of aligned ZnO nanorod arrays by catalyst-free pulsed laser deposition methods. Chem. Phys. Lett. 2004, 396, 21-26. [CrossRef]

11. Xu, C.; Lee, J.H.; Lee, J.C.; Kim, B.S.; Hwang, S.W.; Whang, D. Electrochemical growth of vertically aligned ZnO nanorod arrays on oxidized bi-layer grapheme electrode. CrystEngComm 2001, 13, 6036-6039. [CrossRef]

12. Li, J.; Srinivasan, S.; He, G.N.; Kang, J.Y.; Wu, S.T.; Ponce, F.A. Synthesis and luminescence properties of ZnO nanostructures produced by the sol-gel method. J. Cryst. Growth 2008, 310, 599-603. [CrossRef]

13. Xu, C.X.; Wei, A.; Sun, X.W.; Dong, Z.L. Aligned ZnO nanorods synthesized by a simple hydrothermal reaction. J. Phys. D Appl. Phys. 2006, 39, 1690-1693. [CrossRef]

14. Chen, L.J.; Chuang, Y.J. Hydrothermal synthesis and characterization of hexagonal zinc oxide nanorods with a hexamethylenetetramine (HMTA) template-assisted at a low temperature. Mater. Lett. 2001, 68, 460-462. [CrossRef]

15. Marcu, A.; Viespe, C. Laser-grown $\mathrm{ZnO}$ nanowires for room-temperature SAW-sensor applications. Sens. Actuators B 2014, 208, 1-6. [CrossRef] 
16. Liu, D.F.; Xiang, Y.J.; Wu, X.C.; Zhang, Z.X.; Liu, L.F.; Song, L.; Zhao, X.W.; Luo, S.D.; Ma, W.J.; Shen, J.; et al. Periodic $\mathrm{ZnO}$ nanorod arrays defined by polystyrene microsphere self-assembled monolayers. Nano Lett. 2006, 6, 2375-2378. [CrossRef] [PubMed]

17. Li, L.; Zhai, T.; Zeng, H.; Fang, X.; Bando, Y.; Golberg, D. Polystyrene sphere-assisted one-dimensional nanostructure arrays: Synthesis and applications. J. Mater. Chem. 2011, 21, 40-56. [CrossRef]

18. Xian, F.; Bai, W.; Xu, L.; Wang, X.; Li, X. Controllable growth of ZnO nanorods by seed layers annealing using hydrothermal method. Mater. Lett. 2013, 108, 46-49. [CrossRef]

19. Liu, X.; Wu, X.; Cao, H.; Chang, R.P.H. Growth mechanism and properties of ZnO nanorods synthesized by plasma-enhanced chemical vapor deposition. J. Appl. Phys. 2004, 95, 3141-3147. [CrossRef]

20. Li, W.J.; Shi, E.W.; Zhong, W.Z.; Yin, Z.W. Growth mechanism and growth habit of oxide crystals. J. Cryst. Growth 1999, 203, 186-196. [CrossRef]

(C) 2016 by the authors; licensee MDPI, Basel, Switzerland. This article is an open access article distributed under the terms and conditions of the Creative Commons Attribution (CC-BY) license (http://creativecommons.org/licenses/by/4.0/). 